\title{
Intra-arterial tert-Butyl-Hydroperoxide Infusion Induces an Exacerbated Sensory Response in the Rat Hind Limb and is Associated with an Impaired Tissue Oxygen Uptake
}

\author{
Edward C. T. H. Tan, ${ }^{1,3}$ Harry van Goor, ${ }^{1}$ Soheyl Bahrami, ${ }^{2}$ Andrey V. Kozlov, \\ Martin Leixnering, ${ }^{2}$ Heinz Redl, ${ }^{2}$ and R. Jan A. Goris ${ }^{1}$
}

\begin{abstract}
The objective of this study was to investigate oxidative stress and oxygen extraction mechanisms in an animal model of continuous intra-arterial infusion of a free radical donor and in an in vitro model using isolated mitochondria. tert-Butyl-hydroperoxide (tert-BuOOH, $25 \mathrm{mM}$ ) was infused for $24 \mathrm{~h}$ in the left hind limb of rats to induce soft tissue damage $(n=8)$. After 7 days, we assessed local sensory response, tissue oxygen consumption, oxygen radicals, and antioxidant levels. In vitro mitochondrial function was measured after stimulation of isolated mitochondria of skeletal muscle cells with increasing doses of tert-BuOOH. tert-BuOOH infusion resulted in an increased skin temperature $(p=0.04)$, impaired function, and a significantly increased pain sensation $(p=0.03)$. Venous oxygen saturation levels $(p=0.01)$ and the antioxidant ceruloplasmin $(p=0.04)$ were increased. tert-BuOOH inhibited mitochondrial function in vitro. Induction of free radical formation in the rat hind limb results in an exacerbated sensory response and is associated with impaired oxygen extraction, which likely results from mitochondrial dysfunction caused by free radicals.
\end{abstract}

KEY WORDS: rat model; oxygen radicals; oxygen extraction; mitochondrial dysfunction; complex regional pain syndrome.

\section{INTRODUCTION}

Pain after limb injury gradually disappears within days to weeks. There are, however, some patients in which pain remains and becomes chronic as part of the complex regional pain syndrome type I (CRPS I), formerly known as reflex sympathetic dystrophy or Sudeck's dystrophy. It is a painful, potentially disabling syndrome that usually affects the distal part of the extremity. The disorder is characterized by a variety of autonomic and vasomotor disturbances, of which diffuse

\footnotetext{
${ }^{1} 690$ Department of Surgery, Division of Trauma surgery, Radboud University Nijmegen Medical Centre, P.O. Box 9101, 6500 HB, Nijmegen, The Netherlands

${ }^{2}$ Ludwig Boltzmann Institute for Experimental and Clinical Traumatology, Vienna, Austria

${ }^{3}$ To whom correspondence should be addressed at 690 Department of Surgery, Division of Trauma surgery, Radboud University Nijmegen Medical Centre, P.O. Box 9101, 6500 HB, Nijmegen, The Netherlands. E-mail: E.Tan@chir.umcn.nl
}

pain, spreading edema, temperature disturbances, color changes, and functional impairment are most prominent $[1,2]$. There are various theories on the pathophysiology of this process [3]. Among these are immunologic alterations, changes in plasticity of the sympathetic and central nervous system, and neurogenic inflammation. Neurogenic inflammation is caused by mechanical and/ or chemical activation of sensory neurons and/or small diameter sensory nerve fibers. As a result, inflammatory mediators such as substance $\mathrm{P}$ and calcitonin generelated peptide are released from the distal endings of these sensory nerves, causing vasodilatation, plasma extravasation, and hypersensitivity. Various studies have demonstrated that local release of these neuropeptides induces oxidative stress reflected by an excessive production of reactive oxygen and nitrogen species (RONS) [4, 5]. RONS have been associated with neuropathic pain and the development of chronic pain such as in CRPS I [6], but the mechanism of action of RONS involved in the development of pain and the 
underlying mechanisms are not yet fully understood [7, 8]. Recently, we have studied specific RONS-related pathophysiological changes in a chronic constriction injury rat model of neuropathic pain by means of recently developed spin-trap and electron paramagnetic resonance spectroscopy (EPR) techniques [9]. It was found that oxidative stress-induced changes are present not only in the injured sciatic nerve but also in skeletal muscle tissue. A drawback of the chronic constriction injury model is that it resembles CRPS type II (nerve injury present) and not CRPS type I [10].

It has been suggested that RONS play a role in the pathophysiology of CRPS I through impaired oxygen extraction similar to conditions like adult respiratory distress syndrome, systemic inflammatory response syndrome, and multi-organ dysfunction syndrome [1114]. High mixed venous oxygen saturations and elevated lactate levels at rest are characteristic of a condition with impaired oxygen extraction as it reflects the inability of tissue or muscle to utilize oxygen despite sufficient supply [11].

The aim of this study was to investigate oxidative stress, as measured by RONS and antioxidant levels, and oxygen extraction, as measured by blood gas analysis, in a known animal model of free radical-induced soft tissue injury without inducing ischemia, mimicking clinical signs of CRPS I $[15,16]$. The second aim was to relate oxygen extraction to mitochondrial function. This was done using an in vitro model of isolated skeletal muscle mitochondria that were subjected to tert-butyl-hydroperoxide (tert$\mathrm{BuOOH})[17]$.

\section{EXPERIMENTAL PROCEDURES}

\section{Animals}

Sixteen adult male Sprague-Dawley rats (Animal Research Laboratories, Himberg, Vienna, Austria) weighing $350-400 \mathrm{~g}$ and eight adult male SpragueDawley rats (Animal Research Laboratories) weighing between 260 and $300 \mathrm{~g}$ were used for in vivo and in vitro experiments, respectively. The animals were granted free access to standard laboratory chow and water during a 7-day adaptation period after delivery to our experimental unit. All animals were housed at $22^{\circ} \mathrm{C}$ with a $12-\mathrm{h}$ light/dark cycle. Prior to the experiment, the rats were fasted overnight with free access to water. The protocol of the study was approved by the animal protocol review board of Vienna and followed the requirements defined in the Guide for the Care and Use of Laboratory Animals of the National Institutes of Health (publication NIH 86-23, revised 1985).

\section{Study Design}

Rats underwent a 24-h arterial infusion of tert$\mathrm{BuOOH}$ into the hind limb, inducing free radicalassociated soft tissue damage. At day 7, anesthetized experimental (tert-BuOOH-infused) and control rats (no infusion) received catheters in the jugular veins for blood sampling to assess oxygen radicals and the antioxidants ceruloplasmin and transferrin. Both femoral veins were punctured in the experimental animals for blood gas analysis. Thereafter, all rats were killed and biopsies taken from the gastrocnemius muscle to determine RONS and glutathione. Throughout the experimental period, rats were observed daily for (pain) behavior. Skin temperature, hind limb circumference, and mechanical and heat pain responses were measured at day 1 before tert-BuOOH infusion and at day 7 before anesthesia.

\section{Surgical Procedures}

At day 1, eight randomly assigned rats were anesthetized by intraperitoneal injection of ketamine $70-\mathrm{mg} / \mathrm{kg}$ body weight and subcutaneous injection of xylazine $10-\mathrm{mg} / \mathrm{kg}$ body weight. The animals were kept on a temperature-controlled surgical board $\left(38^{\circ} \pm 1^{\circ} \mathrm{C}\right)$ and allowed to breathe spontaneously. The rats in the infusion group $(n=8)$ were anticoagulated intravenously with $100 \mathrm{U} / \mathrm{kg}$ heparin sodium. A polythene cannula (i.d. $0.28 \mathrm{~mm}$; o.d. $0.61 \mathrm{~mm}$, Laboratoire Portex, France) was placed retrogradely in the left superficial epigastric artery. The tip of the catheter was positioned at the junction of the superficial epigastric artery and common femoral artery, thus preventing impairment of arterial blood flow to the hind limb. The catheter was fixed with polyester sutures 6/0 (Dagrofil, Braun, Melsungen, Germany) and sealed with glue (Histoacryl, Braun, Melsungen, Germany). The other end of the cannula was tunneled subcutaneously over the back of the rat to its head and connected to a flexible stainless swivel system. The swivel was connected to an infusion system. The rats were then awaken and placed in a specially equipped box, being able to walk freely in the cage with the possibility of intra-arterial infusion in the hind limb without compromising blood flow. After cannulation, infusion was started immediately. During $24 \mathrm{~h}$, the rats were infused with tert-BuOOH (Sigma, St. Louis, USA) 
dissolved in saline to a final concentration of $25 \mathrm{mM}$ $(\mathrm{pH}$ 6.8) with heparin $(2.5 \mathrm{U} / \mathrm{ml})$ in a final dose of $0.6 \mathrm{mmol}$. Infusion of tert-BuOOH leads to free radical formation and free radical-induced soft tissue damage $[15,18-20]$. After $24 \mathrm{~h}$, the infusion system was disconnected. All rats were monitored daily for spontaneous pain and other abnormal behavior.

At day 7, experimental rats $(n=8)$ and control rats $(n=8)$ were anesthetized by a mixture of $0.8 \%$ isoflurane and room air for the duration of the procedure. The animals were kept on a temperature-controlled surgical board $\left(38^{\circ} \pm 1^{\circ} \mathrm{C}\right)$ and allowed to breathe spontaneously. Following induction of anesthesia, the jugular vein was catheterized under aseptic conditions with a polyethylene catheter (PE50, Clay Adams, Parsippany, NJ, USA) filled with heparinized Ringer's (8 U/ml). A first heparinized blood sample $(1.5 \mathrm{ml})$ was collected for measurements of antioxidants, and blood volume was replaced by $1.5 \mathrm{ml}$ Ringer's solution. Subsequently, the spin trap 1-hydroxy-3-carboxy-pyrrolidine (CPH), detecting superoxide radicals and peroxynitrite radicals (RONS), was intravenously administered in five experimental and five control animals [21]. At the end of the 30 -min $\mathrm{CPH}$ infusion period, blood samples $(1.5 \mathrm{ml})$ from the jugular vein were collected again for measurement of RONS. Blood samples were also drawn by direct puncture of both femoral veins $(2 \times 0.5 \mathrm{ml})$ in experimental rats for blood gas analysis. Thereafter, all animals were killed and a piece of the left (infused) and left (controls) and right (infused contralateral) gastrocnemius muscle was excised and immediately frozen in liquid nitrogen for RONS and glutathione analysis.

\section{Skin Temperature, Limb Circumference, Pain Behavior, and Evoked Pain Responses}

Skin temperature was measured on the plantar side of both hind paws using a surface electrode (diameter= $0.6 \mathrm{~cm}$; Keith, Geneva, Ohio, USA). The circumference of the hind paw just above the ankle was measured using a string. The relative change of the volume of the operated hind limb to the preoperative situation served as a parameter for contour alterations. Color of the left plantar foot was observed and compared to that of the right foot. The neutral position, grasp, and walking function of both hind paws were recorded by observation of each rat for $5 \mathrm{~min}$. The function of the left hind limb was noted as impaired when the rat had either a clench paw, did not show grasping, or showed a shuffling gait, respectively. Observation of pain signs was performed preoperatively and after 7 days after disconnection from the infusion system. Three different pain forms were assessed according to tests performed in the classical neuropathic pain [22] or peripheral inflammation [23, 24] model in the rat: spontaneous pain, mechanically induced pain, and thermally induced pain. Spontaneous pain behavior of rats was observed in a perspex cage of $26 \times 26 \times 26 \mathrm{~cm}$ after a 5-min habituation. The time of different positions of the lesioned paw was noted according to the scale of Attal et al. [25] which varied from 0 (the operated paw is pressed normally on the floor) to 5 (the animal licks the operated paw). The spontaneous pain was calculated by the formula $t_{1}+2 t_{2}+3 t_{3}+4 t_{4}+5 t_{5} / 300 \mathrm{~s}$, where $t_{1}$, $t_{2}, t_{3}, t_{4}$, and $t_{5}$ are the times (in seconds) spent in categories $1,2,3,4$, or 5 , respectively. Mechanical sensitivity was tested by foot withdrawal in response to mechanical stimulation with Von Frey filaments (North Coast Medical, San José, USA) of two bending forces $(5.16$ and $12.5 \mathrm{~g})$. To this end, the rats were placed in a Perspex cage with a wire mesh floor $(26 \times 26 \times 26 \mathrm{~cm})$. After a 5-min accommodation, a Von Frey filament was applied ten times (once every $5 \mathrm{~s}$ ) to the plantar surface of the paw during which the frequency of foot withdrawals was noted [26]. Thermally induced pain was assessed on a heated floor of $40^{\circ} \mathrm{C}\left( \pm 1^{\circ} \mathrm{C}\right)$. Following the 5-min accommodation, the level of thermally induced pain was scored following the next $5 \mathrm{~min}$ according to the pain score of Attal et al. [25]. For example, if the operated paw was pressed normally on the floor during $5 \mathrm{~min}(300 \mathrm{~s})$, this was scored as 0 ; the rat was not in pain. If the rat demonstrated constant licking of his operated paw, this was scored as $5 \times 300 / 300=5$.

\section{Blood Gas Analysis}

Blood gas analysis including oxygen tension $\left(\mathrm{pO}_{2}\right)$, $\mathrm{pH}$, oxygen saturation $\left(\mathrm{SvO}_{2}\right)$, and lactate level was done in heparinized femoral vein blood samples immediately after bilateral puncture using a Radiometer $\mathrm{ABL}$ 625 Blood Gas Analyzer (Copenhagen, Denmark).

\section{Determination of Level of RONS, Ceruloplasmin, and Transferrin in Plasma}

Plasma of jugular vein heparinized blood samples was separated by centrifugation during $10 \mathrm{~min}$ at $3,000 \times g\left(12,000 \mathrm{rpm}\right.$ at $\left.6^{\circ} \mathrm{C}\right)$. Heparin plasma was used for EPR analysis $[27,28]$. Three hundred fifty microliters of plasma was put in a 1-ml syringe and 
immediately frozen in liquid nitrogen. The sample was then pressed out of the syringe and put in a liquid nitrogen Dewar for EPR analysis. The EPR spectra of RONS (CP adducts) were assessed at liquid nitrogen temperature as described in detail previously [27, 28] using a Bruker EMX EPR spectrometer at the following setting: microwave frequency $9.431 \mathrm{GHz}$, modulation frequency $100 \mathrm{kHz}$, microwave power $31 \mathrm{~mW}$, modulation amplitude $15 \mathrm{G}$, gain $10^{5}$. The double integrals of transferrin ( $g$-factor 4.31) and ceruloplasmin ( $g$-factor 2.05) signals were calculated and compared with those obtained from standard iron(III) and $\mathrm{Cu}$ (II) complexes. The standard iron complexes were prepared by mixing $10 \mathrm{mmol}$ desferrioxamine $\mathrm{B}$ with different amounts of iron ions $\left(\mathrm{FeSO}_{4} \cdot 7 \mathrm{H}_{2} \mathrm{O}\right)$. Desferrioxamine iron complex formed in this mixture was used as standard. Standard $\mathrm{Cu}(\mathrm{II})$ solutions were prepared by adding different amounts of copper ions $\left(\mathrm{CuSO}_{4} \cdot 5 \mathrm{H}_{2} \mathrm{O}\right)$ to $10 \mathrm{mmol}$ diethyldithiocarbamate (DETC) solved in $10 \%$ bovine serum albumin. Copper DETC complex formed in this mixture was used as standard. The final iron/copper concentrations ranged from 0 to $25 \mu \mathrm{M}$. Upon reaction with RONS, CP-H is transformed into a stable $\mathrm{CP}^{\circ}$ radical (3-carboxy-proxyl). Standard solutions of 3carboxy-proxyl were used to quantify RONS levels in plasma.

\section{RONS and Glutathione in Skeletal Muscle Tissue}

For RONS analysis, a small piece of skeletal muscle tissue (approximately $350 \mu \mathrm{l}$ ) was put in a 1-ml syringe and immediately frozen in liquid nitrogen. The sample was then pressed out of the syringe and put in a liquid nitrogen Dewar for EPR analysis as described in the previous paragraph.

For glutathione analysis, the remaining tissue sample was frozen in liquid nitrogen and homogenized in $0.4 \mathrm{M} \mathrm{HClO}_{4}$ using a ball mill. After centrifugation, acid extracts were stored at $-20^{\circ} \mathrm{C}$ or analyzed immediately by means of ion-pair reversed phase HPLC with electrochemical detection. The HPLC system included a Spherisorb S3ODS-2 column $(3 \mu \mathrm{m}, 125 \times 4 \mathrm{~mm}$ ID; Phenomenex, Torrance, CA, USA), a Rheodyne 7125 injector (Rheodyne, Cotati, CA, USA), a PU-980 HPLC pump (Jasco, Great Dunmow, UK), a pulsation dampener (Shodex, Tokyo, Japan), and a Coulochem 5100 A electrochemical detector (ESA, Bedford, MA, USA) equipped with a 5011 analytical cell $(+0.4$ V). Data acquisition and analysis was done with an analog interface AI 406 and System Gold software (both
Beckman Coulter, Fullerton, CA, USA). The mobile phase consisted of $0.1 \mathrm{~mol} / 1$ sodium acetate, $0.1 \mathrm{~mol} / 1$ sodium hydrogen phosphate, $400 \mathrm{mg} / 1 \mathrm{SDS}$ adjusted to pH 2.0, and $2.5 \%$ acetonitrile $(v / v)$. Calibration curves for reduced glutathione (GSH) were established daily. Oxidized glutathione (GSSG) was measured after enzymatic reduction with the following assay: $100 \mu \mathrm{l}$ acid extract were incubated with $50 \mu \mathrm{L} 2.5 \mathrm{mmol} \mathrm{N}$ ethylmaleinimid (NEM) and $760 \mu \mathrm{l} 0.1 \mathrm{M}$ phosphate buffer, $\mathrm{pH} 7.0$, to mask endogenous GSH. Excess of NEM was exhausted with $50 \mu \mathrm{l} 3 \mathrm{mM}$ sodium 2mercaptoethanesulfonate. GSSG was reduced to GSH by addition of $20 \mu \mathrm{l} 2 \mathrm{mM}$ NADPH and $20 \mu \mathrm{l} 12 \mathrm{U}$ glutathione reductase, and GSH was measured by HPLC. Glutathione levels were corrected for skeletal muscle wet weight and protein content in order to correct for skeletal muscle oedema.

\section{Study Design In Vitro Experiment}

Eight adult male Sprague-Dawley rats (Animal Research Laboratories) weighing $280 \pm 21$ g were killed and the hind paw skeletal muscles were quickly harvested and stored. Rat skeletal muscle mitochondria were prepared similarly as described previously with heart mitochondria [17]. Isolated skeletal muscle mitochondria were incubated with tert-BuOOH and subjected to various reagents in a closed system in vitro to assess changes in the rate of oxygen consumption.

\section{MITOCHONDRIAL FUNCTION}

Immediately after harvesting, mitochondria were stored at $0^{\circ} \mathrm{C}$ for $4-5 \mathrm{~h}$ in a buffer containing $0.25 \mathrm{M}$ sucrose, $10 \mathrm{mM}$ Tris- $\mathrm{HCl}, 0.5 \mathrm{mM}$ EDTA (pH 7.2), and $0.5 \mathrm{~g} / \mathrm{l}$ essentially fatty acid-free bovine serum albumin (BSA). Respiration rates were determined with an Oxygraph-2k Respirometer (Oroboros Ltd., Innsbruck, Austria). Skeletal muscle mitochondria were first mixed with an incubation buffer containing $80 \mathrm{mM}$ potassium chloride, $5 \mathrm{mM}$ potassium phosphate, $20 \mathrm{mM}$ Tris- $\mathrm{HCl}$, $1 \mathrm{mM}$ DETAPAC, and $0.1 \%$ BSA (pH 7.4). State 2 rate of respiration was defined as the respiration of mitochondria upon addition of a Krebs cycle substrate only. The transition to state 2 respiration was achieved by addition of glutamate/malate $(5+5 \mathrm{mM})$. After respiration reached a steady state, $0.125 \mathrm{mM}$ ADP was added for transition to state 3 respirations. After all ADP was transformed to ATP, the state 4 respiration was achieved. 
The ratio state 3 rate/state 4 rate is called the respiration control index (RCI) as it reflects the coupling of oxidation and phosphorylation. The mitochondria were pre-incubated for 2 min with either increasing concentrations of tert-BuOOH (final concentrations $0-25 \mathrm{mM}$ ) or with double distilled water used as a control. The kinetics of oxygen consumption rate was analyzed using a custom-made Excel program.

\section{STATISTICAL ANALYSIS}

All data were analyzed using SPSS 16.0 and are expressed as mean with standard error of the mean. RONS, transferrin, ceruloplasmin, and glutathione levels were compared between experimental and control rats and in experimental rats between left (infused) and right (infused contra lateral) hind limb using the MannWhitney $U$ test. Skin temperature, limb circumference, and pain responses of the left hind limb were compared with the right hind limb using the Wilcoxon signed rank test for paired samples. This test was also used to compare blood gas analysis data between the left and right hind limbs. For mitochondrial analysis, statistical analysis was performed by one-way ANOVA followed by a post hoc test for the least significant difference. Statistical significance was defined as a $p<0.05$.

\section{RESULTS}

Most rats developed an abnormal gait and posture $(63 \%)$, guarding behavior (63\%), and sudden licking $(75 \%)$ of the hind paw $1-2$ days after the beginning of infusion. Before infusion, skin temperature difference between the left and right hind paws was $0.06^{\circ} \mathrm{C}\left( \pm 0.1^{\circ} \mathrm{C}\right)$. Seven days later, the skin temperature of the infused left hind paw, as compared to the right, was on average $1.7^{\circ} \mathrm{C}$ $\left( \pm 0.4^{\circ} \mathrm{C}, p=0.043\right)$ higher. The average increase of the infused hind paw circumference was $2.3 \%( \pm 1.5 \%$, $p=0.039$ ). The volume increase of the left foot compared to the preoperative situation was $8.2 \pm 3.4 \%$ after 7 days. Color difference was present in $63 \%$ of the rats. Spontaneous pain was almost absent after 1 week. Mechanical stimulation with both 5.16 and $12.5 \mathrm{~g}$ von Frey filaments showed negligible withdrawal reaction before infusion. Seven days after infusion, withdrawal was significantly more frequent when stimulating with the 5.16-g filament [15 withdrawal responses out of 80 applications; $19 \%$ ( $\pm 10 \%$ ), $p=0.068$ ] or the 12.5 -g filament [30 withdrawal responses out of 80 applications; $38 \%( \pm 15 \%), p=0.027]$ compared to before tert-BuOOH infusion. Preoperative observation of the rats on the heated plate showed normal behavior, with a pain score of 0.04 ( $\mathrm{SD} \pm 0.1$ ). Seven days after infusion, the heat pain score of the infused hind paw was significantly increased to $0.76( \pm 0.5, p=0.028)$, whereas the right limb showed a normal response.

\section{Blood Gas Analysis}

Venous oxygen saturation and venous oxygen tension of the infused left side were significantly higher than those of the infused contra lateral right side, and lactate levels on the infused side tended to be higher (Table 1). These findings were compatible with an impairment of oxygen extraction in the infused hind paw.

\section{Levels of RONS, Ceruloplasmin, and Transferrin in Plasma}

The levels of RONS, ceruloplasmin, and transferrin are presented in Table 2. In jugular vein plasma, no difference was observed in RONS levels between infused rats and controls. Jugular vein plasma levels of the antioxidant ceruloplasmin (CP) were significantly higher in infused rats than in controls $(7.04 \pm 1.01$ versus $4.57 \pm 0.51, p=0.037$ ), whereas no differences were observed in transferrin (TR) plasma levels $(23.59 \pm 4.0$ versus $25.82 \pm 2.09, p=0.35$ ) on day 7 . The antioxidant activity $(\mathrm{AOA}=\mathrm{CP} / \mathrm{TR}$ ratio) tended to be higher in infused rats than in controls $(0.31 \pm 0.1$ versus $0.148 \pm$ $0.02, p=0.063)$.

\section{Levels of RONS and Glutathione in Skeletal Muscle Tissue}

In skeletal muscle tissue, no difference was observed in RONS levels between infused left side versus control animals in Table 3. RONS levels, however, were elevated compared to the non-affected right side on day 7 after tert-BuOOH infusion (4.48 \pm

Table 1. Venous Blood Gas Analysis, Left (Infused) Versus Right (Contra Lateral) Hind Paw

\begin{tabular}{lccc}
\hline \multicolumn{1}{c}{ Parameter } & $\begin{array}{l}\text { Infused left } \\
\text { hind limb }\end{array}$ & $\begin{array}{l}\text { Contra lateral } \\
\text { right hind limb }\end{array}$ & $p$ value \\
\hline $\mathrm{pO}_{2}(\mathrm{mmHg})$ & $38.25 \pm 1.46$ & $31.38 \pm 1.55$ & 0.012 \\
$\mathrm{pH}$ & $7.36 \pm 0.01$ & $7.36 \pm 0.01$ & 1.0 \\
Lactate $(\mathrm{mmol} / \mathrm{l})$ & $1.35 \pm 0.13$ & $1.21 \pm 0.08$ & 0.12 \\
$\mathrm{~S}_{\mathrm{v}} \mathrm{O}_{2}(\%)$ & $53.4 \pm 1.98$ & $40.3 \pm 2.51$ & 0.012 \\
\hline
\end{tabular}


Table 2. Plasma (Jugular Vein) Concentrations of RONS, Transferrin, Ceruloplasmin, and AOA in tert-BuOOH-Infused Rats and Controls

\begin{tabular}{lcrc}
\hline \multicolumn{1}{c}{ Parameter } & $\begin{array}{l}\text { Infused } \\
\text { Animals }\end{array}$ & \multicolumn{1}{c}{$\begin{array}{c}\text { Control } \\
\text { Animals }\end{array}$} & p value \\
\hline RONS (nmol $/ \mathrm{cm}^{3}$ plasma) & $4.36 \pm 0.83$ & $4.70 \pm 0.18$ & 0.51 \\
Transferrin $(\mu \mathrm{M} \mathrm{Fe}(\mathrm{III}))$ & $23.59 \pm 4.0$ & $25.82 \pm 2.09$ & 0.35 \\
Ceruloplasmin $(\mu \mathrm{M} \mathrm{Cu}(\mathrm{II}))$ & $7.04 \pm 1.01$ & $4.57 \pm 0.51$ & 0.037 \\
AOA $(\mathrm{CP} / \mathrm{TR}$ ratio) & $0.31 \pm 0.1$ & $0.148 \pm 0.02$ & 0.063 \\
\hline
\end{tabular}

Data are presented as mean and standard error of the mean

0.73 versus $2.53 \pm 0.14, p=0.11)$. Glutathione levels tended to be higher in infused rats than in controls and in the contralateral right side $(7.22 \pm 0.75$ versus $5.38 \pm$ $0.35, p=0.08$ ).

\section{Mitochondrial Function}

tert-BuOOH had a pronounced inhibitory effect on mitochondrial function in state 3 with increasing doses of tert-BuOOH (Fig. 1). The effect was non-significant in state 2. The RCI, reflecting the coupling of oxidation and phosphorylation in mitochondria, was significantly decreased. This decrease was due to a reduced rate of respiration in state 3 .

\section{DISCUSSION}

This study demonstrates that local induction of oxygen free radical formation results in a chronic state of both local and systemic oxidative stress and impaired oxygen extraction. The same inducer of free radicals impairs mitochondrial function by interfering with ATP synthesis, indicating a possible mode of action inducing oxidative stress. The data confirm that continuous intraarterial infusion of a pro-oxidant compound causes long-term behavior in rats that is indicative of chronic pain, increased sensitivity for non-painful stimuli, and elevated skin temperature. These are all elements of

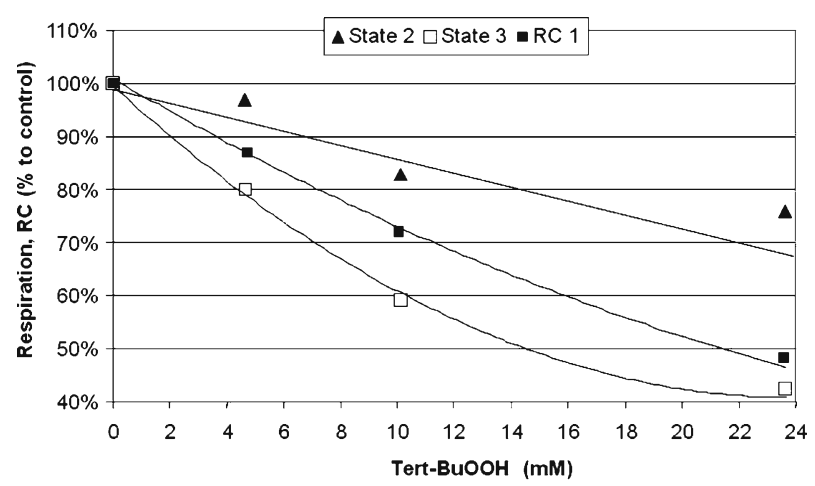

Fig. 1. Dose effect of tert-BuOOH on the respiration rate in state 2 and state 3 and the respiratory control index $(R C I)$ in rat skeletal muscle mitochondria. Respiration and RCI are both expressed in percentage to control values (in the absence of tert-BuOOH). State 2 rate of respiration was defined as the respiration of mitochondria upon addition of a Krebs cycle substrate only.

CRPS I. Signs of chronic pain and inflammation in the rat hind paw in this locally induced oxygen free radical model are similar to those observed in animal models of chronic neuropathic pain, such as the chronic constriction injury model [22].

tert-BuOOH was chosen because it reportedly induces oxidative tissue injury in hepatocytes, renal tubules, the brain, and skeletal muscle [19, 20, 29-31]. tert-BuOOH is metabolized in the cell by GSH peroxidase to glutathione disulfide (GSSG) and tertbutanol. However, GSH can be overwhelmed by using an excess tert-BuOOH, leading to the formation of the free radicals tert-butoxyl and tert-butylperoxyl [18]. The free radical derivatives of tert-BuOOH can induce oxidative injury as a result of lipid peroxidation and mitochondrial dysfunction [19, 20]. In a previous study of infusion of the vehicle of tert-BuOOH (saline with heparin), no signs or symptoms of neuropathic pain were found, histology of skeletal muscle and arteries was unaffected, and there was no increase in vascular permeability as measured by ${ }^{99 m} \mathrm{Tc}-\operatorname{IgG}[15,16]$.

Table 3. Muscle Tissue Concentrations of RONS and GSH in tert-BuOOH-Infused Rats Left Infused Limb Versus Right not Infused ContraLateral Hind Limb and Left Infused Hind Limb Versus Left Hind Limb of Controls Animals

\begin{tabular}{lccr}
\hline & \multicolumn{2}{c}{ Experimental animals } & \multicolumn{2}{c}{$\begin{array}{c}\text { Control animals } \\
\text { Parameter }\end{array}$} & Contralateral right hind limb & Left hind limb \\
\cline { 2 - 5 } RONS (nmol $/ \mathrm{cm}^{3}$ tissue) & $4.48 \pm 0.73$ & $2.53 \pm 0.14$ & $5.49 \pm 0.78$ \\
GSH (U/mg protein) & $7.22 \pm 0.75$ & $5.38 \pm 0.35$ & $0.11 / 0.51$ \\
\hline
\end{tabular}

$P$ value indicates left versus right hind limb and infused versus control animal, respectively 
Accordingly, we have chosen to use only a non-infusion group as control.

Day 7 was chosen for long-term measurement of changes in both oxidant and antioxidant activity induced by 24-h infusion of tert-BuOOH because signs and symptoms of inflammation are still present on this day [32], which was confirmed by the present study. Seven days after infusion, RONS levels in femoral vein plasma of affected hind paws were not higher than those found in controls, challenging our hypothesis. However, measurement of free radical concentrations is difficult because they are extremely short-lived and only produced in minute quantities. Moreover, jugular vein plasma levels of ceruloplasmin were found to be higher in infused rats than in controls, indicating an increased level of systemic antioxidant activity abolishing free radical formation. It is not known when this compensatory response commences during the 7-day period of the experiment. Multiple timerelated observations and measurements would be needed to adequately characterize the biological response to tert$\mathrm{BuOOH}$ infusion.

We have found significantly elevated venous oxygen saturation levels and a tendency of higher venous lactate levels in the infused hind limb 7 days after tert$\mathrm{BuOOH}$ infusion. High mixed venous oxygen saturations and elevated lactate levels at rest are characteristic of a condition with impaired oxygen extraction as it reflects the inability of tissue or muscle to utilize oxygen despite sufficient supply [11]. There are several causes for the high saturation levels: first, a deficient autoregulation of the microcirculation, resulting in a widely open capillary bed, while only a small fraction of the oxygen supplied is consumed; second, the presence of an increased flow through non-nutritive pathways, such as through arteriovenous anastomoses [33]; third, a diffusion problem for oxygen between the erythrocytes and the mitochondria, probably located in the endothelial cell and capillary basement membrane. Finally, reduced oxygen extraction may be present due to mitochondrial dysfunction. With respect to the first possibility, no published reports are available for a defective autoregulation within healthy skeletal muscle in human or rats. As to the second possibility, arteriovenous anastomoses were proven to be present in cat skeletal muscle [34], but were not found in human temporal skeletal muscle [35]. We also could not find this type of information on rats. As to the possibility of a diffusion problem, we observed in this animal model that most arteries were normal, although in previous experiments at day 7, some necrosis of endothelial cells and medial layers of the vascular wall were observed [32]. In this study, histological analysis revealed normal arteries, making a diffusion problem unlikely. Mitochondrial dysfunction remains a plausible cause for the high $\mathrm{S}_{\mathrm{v}} \mathrm{O}_{2}$ levels found. tert-BuOOH-induced oxidative stress is known to damage mitochondria by mitochondrial swelling, resulting in mitochondrial dysfunction and reduction of their respiratory activity [36]. The observed mitochondrial swelling was attributed to an increased inner mitochondrial membrane permeabilization through protein and lipid peroxidation. In the present in vitro experiments, tert-BuOOH impaired respiratory function mitochondria due to decreased respiration in state 3 , reflecting the rate of ATP synthesis, and did not lower state 2 respiration, reflecting the permeability of the mitochondrial membrane. This implies that the mitochondrial energy generating system, reflected by state 3 respiration and the ATP production, is a target for RONS in this model. These data clearly show that tert-BuOOH affects complex I of mitochondria inhibiting the electron transfer. Combining data from both experiments support the concept of tert-BuOOH-mediated mitochondrial dysfunction, causing impaired oxygen extraction. This concords with recently published studies showing that the contribution of the mitochondria in neuropathic pain was ATP-dependent and not dependent on inflammatory markers [37].

It was hypothesized that signs and symptoms of chronic pain syndromes are caused by impaired oxygen extraction secondary to RONS-induced mitochondrial dysfunction. An argument in favor of our hypothesis on the involvement of free radicals in the development of signs and symptoms in this rat model of chronic pain is the reduction of pain sensation, skeletal muscle and nerve damage, and the shortened repair periods after administration of the free radical scavenger $\mathrm{N}$-acetyl-Lcysteine, as shown in a previous study [32]. An argument challenging our hypothesis regards the possible microvascular dysfunction in skeletal muscle which is associated with allodynia due to muscle ischemia [38]. Indeed, we have observed after 1 week some degree of skeletal muscle necrosis, though the degree of tissue necrosis was variable in our rats and not very profound [32].

In conclusion, this study shows that tert-BuOOH, an inducer of oxidative stress and increased RONS generation, causes behavior indicative of chronic pain in the rat hind limb, increased responsiveness to otherwise non-painful mechanical/thermal stimuli, as well as increased skin temperature. These changes are associated with an impaired oxygen extraction, which may result from 
mitochondrial dysfunction caused by free radicals as shown in the in vitro experiment.

\section{ACKNOWLEDGMENT}

We thank Carina Weber, Tricia Behling, Mohammed Jafarmadar (Ludwig Boltzmann Institute for Experimental and Clinical Traumatology), Henk ter Laak, and Lilian Eshuis (Radboud University Nijmegen Medical Centre) for their excellent technical assistance.

Open Access. This article is distributed under the terms of the Creative Commons Attribution Noncommercial License which permits any noncommercial use, distribution, and reproduction in any medium, provided the original author(s) and source are credited.

\section{REFERENCES}

1. Wasner, G., J. Schattschneider, and R. Baron. 2002. Skin temperature side differences-A diagnostic tool for CRPS? Pain 98: 19-26.

2. Veldman, P.H.J.M., H.M. Reynen, I.E. Arntz, and R.J.A. Goris. 1993. Signs and symptoms of reflex sympathetic dystrophy: Prospective study of 829 patients. Lancet 342: 1012-1016.

3. Jänig, W., and R. Baron. 2003. Complex regional pain syndrome: Mystery explained? Lancet Neurology 2: 687-697.

4. Said, S.I. 1990. Neuropeptides as modulators of injury and inflammation. Life Sciences 47: L19-L21.

5. Kramer, J.H., C. Spurney, M. Iantorno, C. Tziros, I.T. Mak, M.I. Tejero-Taldo, J.J. Chmielinska, A.M. Komarov, and W.B. Weglicki. 2009. Neurogenic inflammation and cardiac dysfunction due to hypomagnesemia. American Journal of the Medical Sciences 338: 22-27.

6. Eisenberg, E., S. Shtahl, R. Geller, A.Z. Reznick, O. Sharf, M. Ravbinovich, A. Erenreich, and R.M. Nagler. 2008. Serum and salivary oxidative analysis in complex regional pain syndrome. Pain 138: 226-232.

7. Guedes, R.P., A.S. Araujo, D. Janner, A. Bello-Klein, M.F. Ribeiro, and W.A. Partata. 2008. Increase in reactive oxygen species and activation of Akt signaling pathway in neuropathic pain. Cellular and Molecular Neurobiology 28: 1049-1056.

8. Wang, J., V. Cochran, S. Abdi, J.M. Chung, K. Chung, and H.K. Kim. 2008. Phenyl $N$-t-butylnitrone, a reactive oxygen species scavenger, reduces zymosan-induced visceral pain in rats. Neuroscience Letters 439: 216-219.

9. Tan, E.C., S. Bahrami, A.V. Kozlov, H.A. Kurvers, H.J. ter Laak, H. Nohl, H. Redl, and R.J. Goris. 2009. The oxidative response in the chronic constriction injury model of neuropathic pain. The Journal of Surgical Research 152: 84-88.

10. Stanton-Hicks, M., W. Janig, S. Hassenbusch, J.D. Haddox, R. Boas, and P. Wilson. 1995. Reflex sympathetic dystrophy: Changing concepts and taxonomy. Pain 63: 127-133.

11. Goris, R.J.A. 1998. Reflex sympathetic dystrophy: Model of a severe regional inflammatory response syndrome. World Journal of Surgery 22: 197-202.
12. Schumacker, P.T., and S.M. Cain. 1987. The concept of a critical oxygen delivery. Intensive Care Medicine 13: 223-229.

13. Goode, H.F., and N.R. Webster. 1993. Free radicals and antioxidants in sepsis. Critical Care Medicine 21: 1770-1776.

14. Levy, R.J., and C.S. Deutschman. 2007. Cytochrome c oxidase dysfunction in sepsis. Critical Care Medicine 35: S468-S475.

15. van der Laan, L., P.J. Kapitein, W.J. Oyen, A.A. Verhofstad, T. Hendriks, and R.J. Goris. 1997. A novel animal model to evaluate oxygen derived free radical damage in soft tissue. Free Radical Research 26: 363-372.

16. van der Laan, L., P.J.C. Kapitein, A.A.J. Verhofstad, T. Hendriks, and R.J.A. Goris. 1998. Clinical signs and symptoms of acute reflex sympathetic dystrophy in one hindlimb of the rat, induced by infusion of a free-radical donor. Acta Orthopaedica Belgica 64: $210-217$.

17. Kozlov, A.V., K. Staniek, S. Haindl, C. Piskernik, W. Ohlinger, L. Gille, H. Nohl, S. Bahrami, and H. Redl. 2006. Different effects of endotoxic shock on the respiratory function of liver and heart mitochondria in rats. American Journal of Physiology Gastrointestinal and Liver Physiology 290: G543-G549.

18. Sies, H. 1985. Chapter 4: Hydroperoxides and thiol oxidants in the study of oxidative stress in intact cells and organs. In Oxidative stress, ed. H. Sies, 73-89. London: Academic.

19. Schnellman, R.G. 1988. Mechanisms of $t$-butyl hydroperoxideinduced toxicity to rabbit renal proximal tubules. Cell Physiology 24: C28-C33.

20. Chang, M.L., L. Klaidman, and J.D. Adams. 1995. Age-dependent effects of $t \mathrm{BuOOH}$ on glutathione disulfide reductase, glutathione peroxidase, and malondialdehyde in the brain. Molecular and Chemical Neuropathology 26: 95-106.

21. Kozlov, A.V., L. Szalay, F. Umar, B. Fink, K. Kropik, H. Nohl, H. Redl, and S. Bahrami. 2003. EPR analysis reveals three tissues responding to endotoxin by increased formation of reactive oxygen and nitrogen species. Free Radical Biology and Medicine 34: $1555-1562$.

22. Bennett, G.J., and Y.K. Xie. 1988. A peripheral mononeuropathy in rat that produces disorders of pain sensation like those seen in man. Pain 33: 87-107.

23. Safieh Garabedian, B., S. Poole, A. Allchorne, J. Winter, and C.J. Woolf. 1995. Contribution of interleukin-1 beta to the inflammation-induced increase in nerve growth factor levels and inflammatory hyperalgesia. British Journal of Pharmacology 115: $1265-1275$.

24. Perkins, M.N., D. Kelly, and A.J. Davis. 1995. Bradykinin B1 and B2 receptor mechanisms and cytokine-induced hyperalgesia in the rat. Canadian Journal of Physiology and Pharmacology 73: 832936.

25. Attal, N., F. Jazat, V. Kayser, and G. Guilbaud. 1990. Further evidence for 'pain-related' behaviours in a model of unilateral peripheral mononeuropathy. Pain 41: 235-251.

26. Chaplan, S.R., F.W. Bach, J.W. Pogrel, J.M. Chung, and T.L. Yaksh. 1994. Quantitative assessment of tactile allodynia in the rat paw. Journal of Neuroscience Methods 53: 55-63.

27. Kozlov, A.V., O.A. Azizova, and Y.A. Vladimirov. 1991. Radiospectroscopic analysis of serum proteins and its potential for use in medical diagnosis. Sov Med Rev B Physicochemical Aspects of Med 2: 45-73.

28. Hubel, C.A., A.V. Kozlov, V.E. Kagan, R.W. Evans, S.T. Davidge, M.K. McLaughlin, and J.M. Roberts. 1996. Decreased transferrin and increased transferrin saturation in sera of women with preeclampsia: Implications for oxidative stress. American Journal of Obstetrics and Gynecology 175: 692-700.

29. Buc-Calderon, P., I. Latour, and M. Roberfroid. 1991. Biochemical changes in isolated hepatocytes exposed to tert-butyl hydroperoxide. Implications for its cytotoxicity. Cell Biology and Toxicology 7: $129-143$. 
30. Ji, L.L., and R. Fu. 1992. Responses of glutathione system and antioxidant enzymes to exhaustive exercise and hydroperoxide. Journal of Applied Physiology 72: 549-554.

31. Menshikova, E.V., V.B. Ritov, N.V. Gorbunov, G. Salama, H.G. Claycamp, and V.E. Kagan. 1999. Nitric oxide prevents myoglobin/ tert-butyl hydroperoxide-induced inhibition of $\mathrm{Ca}^{2+}$ transport in skeletal and cardiac sarcoplasmic reticulum. Annals of the New York Academy of Sciences 874: 371-385.

32. van der Laan, L., W.J.G. Oyen, A.A.J. Verhofstad, E.C.T.H. Tan, H.J. ter Laak, A. Gabreels-Festen, T. Hendriks, and R.J.A. Goris. 1997. Soft tissue repair capacity after oxygen-derived free radicalinduced damage in one hindlimb of the rat. The Journal of Surgical Research 72: 60-69.

33. Clark, M.G., S. Rattigan, L.H. Clerk, M.A. Vincent, A.D. Clark, J. M. Youd, and J.M. Newman. 2000. Nutritive and non-nutritive blood flow: Rest and exercise. Acta Physiologica Scand. 168: 519-530.
34. Myrhage, R., and E. Eriksson. 1980. Vascular arrangements in hind limb muscles of the cat. Journal of Anatomy 131: 1-17.

35. Cheung, L.K. 1996. The blood supply of the human temporalis muscle: A vascular corrosion cast study. Journal of Anatomy 189 (Pt 2): 431-438.

36. Castilho, R.F., A.J. Kowaltowski, A.R. Meinicke, and A.E. Vercesi. 1995. Oxidative damage of mitochondria induced by Fe(II)citrate or $t$ butyl hydroperoxide in the presence of $\mathrm{Ca}^{2+}$ : Effect of coenzyme Q redox state. Free Radical Biology and Medicine 18: 55-59.

37. Joseph, E.K., and J.D. Levine. 2006. Mitochondrial electron transport in models of neuropathic and inflammatory pain. Pain 121: 105-114.

38. Laferriere, A., M. Millecamps, D.N. Xanthos, W.H. Xiao, C. Siau, M.M. de, C. Sachot, J.V. Ragavendran, F.J. Huygen, G.J. Bennett, et al. 2008. Cutaneous tactile allodynia associated with microvascular dysfunction in muscle. Molecular Pain 4: 49. 